colonic muscle. ${ }^{2}{ }^{5}$ Flatulence, abdominal fullness, and intermittent diarrhoea may also owe their origin to a disordered intestinal motility caused by a low-residue diet. ${ }^{9}$ The addition of alverine citrate to the bulk-forming sterculia was also found to be clinically effective in relieving this group of symptoms. Hence, this preparation may be used in the treatment of diverticular disease in patients who cannot tolerate millers' bran.

We are grateful to Norgine Limited for supplies of preparations A (Normacol Special) and B (Normacol Antispasmodic). This work was done during the tenure of Scottish Hospital Endowments Research Trust grant No 418 to $\mathrm{Mr}$ A N Smith. Lieutenant-Colonel G S Srivastava participated in this work while on two years' secondment to the UK from the Indian Army Medical Corps.

Requests for reprints should be sent to Dr A N Smith.

\section{References}

${ }^{1}$ Painter, N S, Master of Surgery thesis, University of London, 1962.

2 Painter, N S, Annals of Royal College of Surgeons of England, 1964, 3498.

${ }^{3}$ Painter, N S, et al, Gastroenterology, 1965, 49, 169.

4 Morson, B C, British fournal of Radiology, 1963, 36, 385.

${ }^{3}$ Painter, N S, British Medical fournal, 1968, 3, 475.

${ }^{6}$ Holdstock, D J, Misiewicz, J J, and Waller, S L, Gut, 1969, 10, 19.

' Findlay, J M, et al, Lancet, 1974, 1, 146.

${ }^{8}$ Kirwan, W O, et al, British Medical fournal, 1974, 4, 187.

9 Painter, N S, Almeida, A Z, and Colebourne, K W, British Medical fournal, 1972, 2, 137.

11 Smith, A N, Giannakos, V, and Clarke, S, fournal of the Royal College of Surgeons of Edinburgh, 1971, 16, 276.

${ }^{11}$ Hinton, J M, Lennard-Jones, J E, and Young, A C, Gut, 1969, 10, 842.

12 Ireson, J D, et al, Pharmacological Research Communications, 1972, 4, 191.

${ }^{13}$ Smith, A N, Attisha, R P, and Clarke, S, American fournal of Digestive Diseases, 1971, 16,728

${ }^{14}$ Burkitt, D P, Walker, A R P, and Painter, N S, Lancet, 1972, 2, 1408.

15 Painter, N S, and Burkitt, D P, British Medical fournal, 1971, 2, 450.

\title{
Metronidazole in prevention and treatment of bacteroides infections after appendicectomy
}

\author{
A $T$ WILLIS, I R FERGUSON P H JONES K D PHILLIPS, P V TEARLE, R B BERRY, \\ R V FIDDIAN, D F GRAHAM, D H C HARLAND, D B INNES, W M MEE, \\ R L ROTHWELL-JACKSON, IRENE SUTCH, CAROL KILBEY, DEBORAH EDWARDS
}

British Medical fournal, 1976, 1, 318-321

\section{Summary}

The frequency of non-clostridial anaerobic infection was studied in 95 patients who had undergone acute appendicectomy: 49 received prophylactic metronidazole and 46 received placebo. Anaerobic infection did not develop in any of the metronidazole-treated patients, but infections did develop in nine $\left(19^{\circ}{ }_{0}\right)$ of the 46 controls. Metronidazole is conveniently administered by suppository to patients who cannot take oral drugs. Five patients with intra-abdominal infections caused by non-clostridial anaerobes were successfully treated with metronidazole.

\section{Introduction}

Acute appendicitis is a common condition that usually requires emergency surgery. The commonest complication of appendi-

\footnotetext{
*Department of Clinical Microbiology (Public Health Laboratory), Luton and Dunstable Hospital, Luton LU4 ODZ

A T WILLIS, MD, FRACP, consultant microbiologist

I R FERGUSON, MB, DIPBACT, assistant bacteriologist

$P$ H JONES, MB, CHB, trainee bacteriologist

K D PHILLIPS, BSC, senior scientific officer

P V TEARLE, AIMLT, technician
}

Department of Surgery, Luton and Dunstable Hospital, Luton LU4 ODZ

R B BERRY, FRCS, surgical registrar

R V FIDDIAN, FRCS, $\mathrm{MCH}$, consultant surgeon

D F GRAHAM, FRCS, surgical registrar

D H C HARLAND, FRCS, consultant surgeon

D B INNES, FRCS, surgical registrar

W M MEE, FRCS, consultant surgeon

R L ROTHWELL-JACKSON, FRCS, $\mathrm{MCH}$, consultant surgeon

Pharmacy, Luton and Dunstable Hospital, Luton LU4 0DZ

IRENE SUTCH, MPS, district pharmaceutical officer

CAROL KILBEY, BPHARM, MPS, staff pharmacist

DEBORAH EDWARDS, BPHARM, MPS, staff pharmacist cectomy is undoubtedly surgical sepsis, the incidence of which may vary from $4{ }^{\circ}$ o for normal appendices to $77 \%$ for gangrenous or perforated appendices. The average frequency of postoperative infection is probably about $30^{\circ}{ }_{0} 0^{1+4}$ Although some of these infections are relatively trivial they often delay discharge from hospital and subsequent return to work, and some are serious or even life-threatening. In an effort to reduce the incidence of sepsis after appendicectomy surgeons have used various topical and systemic prophylactic antibacterial agents. Topical prophylactic agents have included ampicillin, Polybactrin, and tetracycline, while ampicillin, tetracycline, penicillin, lincomycin, and clindamycin have all been used systemically. ${ }^{35-10}$

Although none of the prophylactic procedures reported are consistently effective, appropriate systemic antibiotics generally reduce the incidence of intra-abdominal sepsis, while appropriate local treatment reduces the incidence of wound infection. ${ }^{36}$

Most reports on the chemoprophylaxis of sepsis after appendicectomy have been concerned solely with clinical aspects of infection and have not considered the nature of the infecting agents. This is unfortunate because in this condition the effectiveness of any prophylactic antibiotic clearly depends on its spectrum of antibacterial activity. It is still widely believed that abdominal infections after surgery are usually caused by the Enterobacteraceae and enterococci. As long ago as 1898, however, Veillon and Zuber ${ }^{11}$ reported on the common occurrence of non-sporing anaerobes in cases of appendicitis, an observation that was subsequently confirmed and amplified. ${ }^{12}$ It was also shown ${ }^{13}$ that the foul-smelling pus, which is so commonly associated with these infections, is always due to non-sporing anaerobes, and that true Escherichia coli pus is odourless.

Recently there has been an increasing awareness of the importance of non-sporing anaerobes as the major cause of sepsis after surgery of the gastrointestinal tract or female genital tract. $^{14-16}$ This matter has been highlighted in relation to appendicitis by Leigh et al, ${ }^{9}$ who recovered Bacteroides fragilis from $90^{\circ},{ }_{0}$ of wound infections after appendicectomy. Our own experience leaves no room for doubt that most infections that develop after intestinal surgery are caused by non-sporing anaerobes. 
Recent studies carried out at the Luton and Dunstable Hospital have shown that systemic metronidazole is highly effective in preventing the development of postoperative sepsis due to anaerobes in gynaecological patients. ${ }^{17}{ }^{1 \times}$ We report here the clinical and bacteriological findings of a double-blind trial of metronidazole that was aimed at assessing the value of the drug in the prophylaxis of sepsis after appendicectomy.

\section{Patients and methods}

All patients entering the hospital for emergency appendicectomy were admitted to the trial provided that there was no recent history of antibiotic or metronidazole treatment. The study was conducted as a double-blind trial in which metronidazole was compared with a placebo. Patients were randomly allocated to the two groups.

\section{CLINICAL MANAGEMENT}

Before operation-As part of the preoperative medication each patient was given a suppository rectally which contained either metronidazole or a placebo. A sample of blood for metronidazole assay was collected during induction of the anaesthetic.

At operation-Although no uniform surgical technique of appendicectomy was used by the four surgical teams taking part the following standard procedures were adopted at each operation: (a) paired swabs of the peritoneal surface of the appendix fossa were taken immediately on entry into the peritoneal cavity; $(b)$ paired swabs of the peritoneum over the appendix stump were taken after completion of the operation (all swabs were held in Stuart's transport medium pending bacteriological examination); (c) the proximal half of the appendix was submitted for bacteriological examination; $(d)$ pus or peritoneal exudate, when present, was collected for bacteriological examination; (e) apart from a routine preoperative skin preparation, no other antibacterial agents were used at operation; and ' $f$ ) after the operation the surgeon recorded essential details of operative technique and clinical findings on a form.

After operation-Patients received metronidazole or placebo until the end of the seventh day after operation according to the schedule outlined below. A sample of blood for metronidazole assay was also collected on the first day after operation. Careful daily clinical records were kept of the patients' progress, special attention being paid to any evidence of clinical infection. Additional specimens for bacteriological study (urine, sputum, surgical wound swabs, etc) were collected as indicated by the patient's clinical condition. When a patient developed proved anaerobic sepsis we broke the double-blind code to find out whether the patient was receiving placebo or metronidazole. All patients were reviewed two weeks after discharge from hospital, when follow-up ceased.

\section{PROPHYLACTIC REGIMEN}

With the preoperative medication $1 \mathrm{~g}$ of metronidazole or placebo was given rectally in a 4-g Witepsol suppository. ${ }^{18}$ These suppositories consisted of $2 \mathrm{~g}$ of Witepsol 35, $1 \mathrm{~g}$ of Witepsol 75, and $1 \mathrm{~g}$ of metronidazole or placebo. After surgery each patient received one suppository every eight hours until oral feeding began, when metronidazole or placebo was given in tablets-200 $\mathrm{mg}$ three times daily to the end of the seventh day. Children under 12 years received small paediatric suppositories which contained $0.5 \mathrm{~g}$ of metronidazole or placebo.

\section{BACTERIOLOGICAL STUDIES}

Operation specimens were cultured for aerobic and anaerobic bacteria. Some appendices, and all samples of peritoneal exudate and pus, were also examined by gas-liquid chromatography for volatile products of bacterial metabolism. Postoperative specimens were examined as appropriate.

\section{Results}

During 15 weeks 105 patients were admitted to the study; 53 received prophylactic metronidazole and 52 were controls. Over the course of the study 10 patients already accepted into the trial ceased to qualify, either because other antibiotic treatment was begun (five patients) or because the "double-blind" prophylaxis was incomplete (five patients). We therefore analysed 95 patients, 49 of whom received metronidazole (table I).

\section{FREQUENCY OF POSTOPERATIVE INFECTION CAUSED BY ANAEROBES}

Within both groups of patients there were several infections due exclusively to facultative organisms ( $E$ coli, enterococci, and Staphylococcus aureus). Wound infections developed in seven patients (five test patients, two controls), and one patient in the control group had a urinary tract infection. Post-surgical sepsis due to facultative organisms was always superficial, mild, and never foul-smelling.

Anaerobic infection did not develop in any of the 49 patients who received prophylactic metronidazole, but bacteriologically confirmed clinical anaerobic infection developed in nine $(19 \%)$ of the 46 controls. Clinically all of these patients were feverish and ill, and there were copious foul-smelling discharges from their wounds, usually without evidence of superficial inflammation. Although exploration was not undertaken all of these infections were judged to be deep-seated and to be due to non-sporing anaerobes.

Four of the nine controls who developed postoperative anaerobic infections were treated with "watchful expectancy." The fever generally resolved in five to seven days, and the discharge stopped and healing began soon afterwards. In the other five infected patients the infection was severe enough to warrant antibacterial treatment. Reference to the double-blind trial code showed that none of them was receiving prophylactic metronidazole, and the drug was then given therapeutically according to the prophylactic schedule already outlined. In all cases the temperature settled within 24 hours, with subsequent cessation of discharge and uneventful recovery.

\section{OTHER RELATIONSHIPS}

Not surprisingly, acute appendicitis showed itself as a disease of adolescents and young adults, 76 of the 95 patients $(80 \%)$ being 10-30 years old. Also in keeping with earlier reports was the relationship between the incidence of postoperative infection, on the one hand, and the severity of illness and the technical difficulty of surgery, on the other. Nine patients (seven on metronidazole, two on placebo) had gangrenous appendices, eight (two on metronidazole, six on placebo) had technically difficult appendicectomies, and 11 (six on metronidazole, five on placebo) had both gangrenous appendices and difficult operations. Of these 28 patients 12 developed postoperative infections (seven intra-abdominal anaerobic infections, and five aerobic wound infections). Among the remaining 67 patients in whom the appendix was normal or acutely inflamed and appendicectomy was technically easy, there were only four postoperative infections (two intra-abdominal anaerobic infections, and two aerobic wound infections). It was impossible to draw useful conclusions from other analyses owing to the small numbers analysed.

\section{BACTERIOLOGY}

Specimens collected at operation generally indicated clearly those patients at particular risk from postoperative anaerobic sepsis. All the patients who developed intra-abdominal anaerobic infections had bacterial contamination of the peritoneum at the end of the operation;

TABLE I-Some surgical features of 95 appendicectomy patients. Results are numbers of patients

\begin{tabular}{|c|c|c|c|c|c|c|c|c|c|c|}
\hline & & \multirow{2}{*}{$\begin{array}{c}\text { No of } \\
\text { patients }\end{array}$} & \multicolumn{2}{|c|}{ Operation } & \multicolumn{3}{|c|}{ Appendicitis } & \multicolumn{3}{|c|}{ Peritonitis } \\
\hline & & & Easy & Difficult & Normal & Acute & Gangrenous & Local & General & None \\
\hline $\begin{array}{l}\text { Metronidazole group } \\
\text { Control group } \quad . .\end{array}$ & $\therefore$ & $\begin{array}{l}49 \\
46\end{array}$ & $\begin{array}{l}41 \\
35\end{array}$ & $\begin{array}{r}8 \\
11\end{array}$ & $\begin{array}{l}13 \\
15\end{array}$ & $\begin{array}{l}23 \\
24\end{array}$ & $\begin{array}{r}13 \\
7\end{array}$ & $\begin{array}{l}26 \\
18\end{array}$ & $\begin{array}{l}3 \\
1\end{array}$ & $\begin{array}{l}20 \\
27\end{array}$ \\
\hline
\end{tabular}


in seven of these patients the appendix was gangrenous or appendicectomy was difficult, or both. Three other controls who had peritoneal soiling (one of whom fell into the gangrenous and difficult subgroup) did not develop an anaerobic infection, and none of the 34 controls whose peritoneal swabs were sterile developed intra-abdominal infections. No patient in the metronidazole-treated group developed an anaerobic infection, though 14 had peritoneal soiling comparable to that found in control patients, and in nine of these 14 patients the appendix was gangrenous or appendicectomy was difficult, or both.

There was no clear relation between the incidences of peritoneal soiling and aerobic wound infection. Of the seven patients who developed aerobic wound infections three had peritoneal soiling and four had none.

In common with the experience of others, all of the nine patients with intra-abdominal anaerobic infections yielded facultative bacteria in addition to anaerobes. In seven patients, however, obligate anaerobes were overwhelmingly predominant, while in the other two patients in whom anaerobes were judged to be the significant pathogens both groups of organisms were present in about equal numbers. The commonest anaerobes isolated were Bacteroides fragilis (nine patients) and $B$ melaninogenicus (four patients), while facultative bacteria were represented by $E$ coli and related coliform bacteria (nine patients) and by enterococci (four patients). Pseudonomas and Proteus species were not encountered.

Bacteriological examination of the appendix was of little value. In all cases (normal, acute, and gangrenous) a normal faecal flora was isolated, and the results of gas-liquid chromatography of appendix extracts were similarly inconclusive. Chromatography analysis of samples of pus, however, provided an early indication of the probable bacterial aetiology of the infection. ${ }^{19}$

\section{SERUM METRONIDAZOLE LEVELS}

Blood samples for metronidazole assay were collected from all of the patients in the control group, and from most of those in the test group. Some samples were missed accidentally, but in the children postoperative sampling was intentionally discontinued early in the study. Assays were performed by May and Baker by the polarographic method. Metronidazole was absent from all samples of blood collected from control patients. The results for the metronidazole group are summarised in table II.

TABLE II-Serum metronidazole levels ( $\mu$ mol $/ l$ ) measured before operation in 29 adults and 10 children and after operation in 33 adults and 5 children who received metronidazole suppositories

\begin{tabular}{ll|c|c|c|c}
\hline & \multicolumn{2}{|c|}{ Adults } & \multicolumn{2}{c}{ Children } \\
\cline { 2 - 5 } & Mean & Range & Mean & Range \\
\hline $\begin{array}{l}\text { Before operation* } \\
\text { After operation }\end{array}$ & $\cdots$ & 30 & $4 \cdot 7-96$ & 44 & $22-73$ \\
& 95 & $26-175$ & 108 & $79-140$ \\
\hline
\end{tabular}

*Blood samples were collected at various intervals 30-150 minutes after administration of metronidazole.

Conversion: SI to traditional units $-1 \mu \mathrm{mol} / 1 \approx 0.17 \mu \mathrm{g} / \mathrm{ml}$

We were concerned only with obtaining adequate blood metronidazole levels, no close attention being paid to the pharmokinetics of the drug. One patient who was receiving metronidazole developed very dark urine-a well-known but uncommon and harmless side effect of metronidazole treatment. ${ }^{20}$ No other side effects were seen.

\section{Discussion}

Although few patients were studied in the trial, our results show clearly that a bactericidal level of metronidazole in the patients' blood sustained during and after operation reduces the frequency of postoperative anaerobic infection.

All nine postoperative anaerobic infections developed in patients who had peritoneal soiling at the end of operation, and in seven of these the appendix was gangrenous or appendicectomy was technically difficult, or both. These are conditions that are known to predispose to anaerobic infection after bowel surgery. Since 46 appendicectomies were performed in the control group, and 49 in the metronidazole-treated group there is no doubt that metronidazole was an effective prophylactic $\left(\%^{2}\right.$ with Yates's correction was significant at the $0.5^{\circ}$, , level).

Although the potential of metronidazole in the treatment of anaerobic infections has been recognised for some time, ${ }^{21}$ its assessment has been delayed by the fact that only an oral preparation has been available. For patients who can take food by mouth oral metronidazole is highly effective in both the prophylaxis and treatment of anaerobic infections. ${ }^{17}{ }^{18}$ Recent independent studies at Newcastle and Luton have shown that the drug may be administered effectively and safely by the intravenous and rectal routes. Ingham et al ${ }^{22}$ described the use of intravenous metronidazole in three patients with serious infections due to $B$ fragilis and the rectal route was used in a patient with septic abortion due to $B$ fragilis after a successful trial of this route in healthy volunteers. ${ }^{18}$ We considered it inappropriate, however, to use the intravenous route for evaluating the drug as a prophylactic agent. From the serum metronidazole levels obtained in patients who received active suppositories it is clear that administration of the drug in this form is therapeutically appropriate. Moreover, there were no side effects, administration was easy for the nursing staff and acceptable to patients, and suppositories could be given to virtually all patients of all ages who could not take anything by mouth-for example, those undergoing preoperative starvation or with paralytic ileus.

The established value of metronidazole in the treatment of non-clostridial anaerobic infections ${ }^{17} 1 *$ was confirmed by its successful use in the treatment of five control appendicectomy patients who required antibacterial treatment for postoperative anaerobic sepsis. The first indication that metronidazole might be of value in the treatment of anaerobic infections followed from the chance observation by Shinn ${ }^{23}$ that the drug was highly effective in the treatment of Vincent's stomatitis. A patient whom Shinn was treating with metronidazole for vaginal trichomoniasis who also had marginal gingivitis showed that at the end of one weeks' treatment she had undergone "a double cure." In our study we had a similar experience with a woman in the test group who was mystified but delighted by the fact that appendicectomy cured her long-standing and intractable vaginal irritation.

The considerable reduction in postoperative morbidity due to metronidazole prophylaxis has not only shortened patients' stay in hospital and thus made available additional beds but has lightened the nursing of patients with serious postoperative sepsis by virtually eliminating it. As with elective gynaecological surgery ${ }^{18}$ we believe that it is improper to withhold metronidazole prophylaxis from patients submitted to appendicectomy.

We thank May and Baker for providing metronidazole, advising on the preparation of suppositories, and assaying serum metronidazole. We are indebted to our anaesthetic colleagues, to the junior surgical staff and to the surgical nursing staff for their willing co-operation.

\section{References}

1 Lancet, 1970, 1, 930

2 Lancet, 1971, 2, 195

3 Margarey, C J, et al, Lancet, 1971, 2, 179.

${ }^{4}$ Airan, M C, Levine, H D, and Sicé, J, Lancet, 1973, 1, 1058.

${ }_{5}^{5}$ Rickett, J W S, and Jackson, B T, British Medical fournal, 1969, 4, 206.

${ }^{6}$ Longland, C J, et al, British fournal of Surgery, 1971, 58, 117.

7 Benson, E A, Brown, G J A, and Whittaker, M, Lancet, 1973, 2, 322.

${ }^{*}$ Bates, T, et al, British fournal of Surgery, 1974, 61, 489.

9 Leigh, D A, Simmons, K, and Norman, E, fournal of Clinical Pathology, 1974, 27, 997.

1" Okubadejo, O A, Abstracts of the 9th International Congress of Chemotherapy, in press.

11 Veillon and Zuber, Archive de Médicene Expérimentale et d'Anatomie Pathologique, 1898, 10, 517.

12. Altemeier, W A, Annals of Surgery, 1938, 107, 517.

13 Altemeier, W A, Annals of Surgery, 1938, 107, 634.

14 Chow, A W, Marshall, J R, and Guze, L B, Obstetrical and Gynecological Survey, 1975, 30, 477.

15 Gorbach, S, and Bartlett, J G, New England Fournal of Medicine, 1974, 290, 1177, 1237, 1289. 
${ }^{16}$ Willis, A T, Young, S E J, and Ferguson, I R, in Infection with Nonsporing Anaerobic Bacteria, ed I Phillips and M Sussman, p 189 London, Churchill, 1974.

17 Study Group, Lancet, 1974, 2, 1540.

18 Study Group, Fournal of Antimicrobial Chemotherapy, in press.

19 Phillips, K D, Tearle, P V, and Willis, A T, in press.
${ }^{20}$ Bruce, T A, fournal of the American Medical Association, 1971, 218, 1832. 1 Tally, F P, Sutter, V L, and Finegold, S M, California Medicine, 1972, $117,22$.

22 Ingham, H R, et al, fournal of Antimicrobial Chemotherapy, 1975, 1, 235. ${ }^{23}$ Shinn, D L S, Lancet, 1962, 1, 1191.

\section{SHORT REPORTS}

\section{Reticulo-endothelial phagocytosis in patients with nephritis}

The reticuloendothelial system (RES) plays an important part in removing circulating immune complexes, particularly those which are large and fix complement.' Such circulating complexes lead to nephritis and various forms of vasculitis." We therefore thought it important to assess the clearance capacity of the reticuloendothelial cells in different types of nephritis. Salky, Mills, and diLuzio ${ }^{3}$ have reported an increased RES clearance for an artificial lipid emulsion in many immunological diseases such as rheumatoid arthritis, and systemic lupus erythematosus, and in rheumatic fever with polyarthritis, but it is more convenient to measure the clearance of heataggregated iodinated human serum albumin. We used this method for studying RES function in renal transplant recipients, ${ }^{4}$ and heataggregated human serum gammaglobulin for studying renal glomerular mesangial cell phagocytosis in animals with experimental nephritis.

\section{Methods and results}

Patients attending the outpatient clinic with nephritis were asked to volunteer for the study. Ward patients convalescing from myocardial infarction were the normal controls, and gave informed consent. Aggregated human serum albumin, containing a tracer quantity of iodinated human serum albumin (Radiochemicals, Amersham), was prepared. ${ }^{1}$ For each test patients were given an intravenous dose of $150 \mathrm{mg}$ sodium iodide to block the thyroid gland, and 10 minutes later they were given intravenously through a Venflon needle iodinated aggregated albumin, $5 \mathrm{mg}$ per $\mathrm{kg}$ body weight. Thereafter $2.0 \mathrm{ml}$ blood samples were taken with precise timing at two-minute intervals for 12 minutes, and again at 15 and 20 minutes, into EDTA anticoagulant. The value for each patient was expressed as the half-time of the clearance in minutes $\left(T_{50}\right)$.

The overall results are presented in the figure, which also illustrates the activity of individual cases. An increased RES clearance capacity, as judged by a shorter half-time of clearance of aggregated albumin, was present in patients with proliferative and membranous nephritis, and also in those with

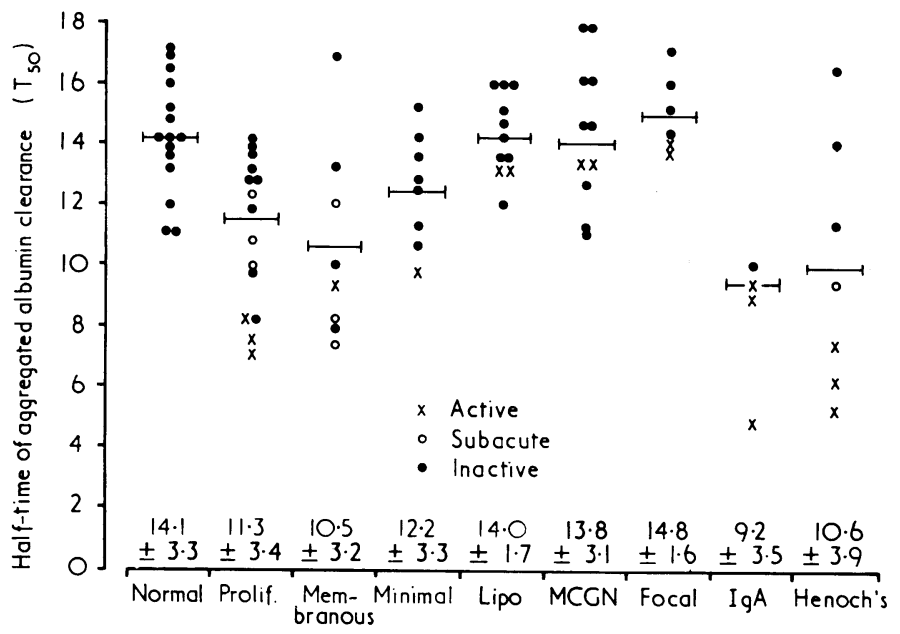

The figure shows the distribution of aggregated albumin half-lives $\left(T_{50}\right)$ in the various categories of nephritis and also whether the patients had active subacute, or inactive disease at the time of study. (The mean values for patients with proliferative and membranous nephritis and for mesangial igA disease and Henoch's nephritis were all significant at $\mathrm{P}<0 \cdot 001$.) mesangial igA disease and with active Henoch-Schönlein disease. Patients with active disease were those with increased RES phagocytosis, even among the patients with focal nephritis whose mean values were in the normal range. Patients with lipodystrophy gave clearance values within the normal range, and three patients with lipodystrophy and mesangiocapillary nephritis had clearances close to the normal values.

\section{Discussion}

Increased RES activity in proliferative and membranous nephritis probably reflects the occurrence of circulating immune complexes or continued antigenic stimulation. Unfortunately there is no way in man for measuring the activity of the mesangial cells, as is the case in animals. Nevertheless, a test for whole body RES phagocytic activity should be useful for assessing the effects of anti-inflammatory drugs

The finding of increased RES activity in mesangial igA disease is important since it explains in part why igA is found in this condition. Mesangial igA disease probably forms part of a spectrum of disease which merges with the Henoch-Schönlein syndrome, and our results (see figure) certainly support this statement. Indeed, probably the mesangial uptake of igA is part of a generalised increase of RES activity, which in turn may be due to some alteration of the igA molecule.

In mesangiocapillary nephritis there is manifest mesangial activity. Nevertheless, none of our cases showed any significant increase of overall RES activity. Moreover, the slower clearances in this group were in patients who also have lipodystrophy. Since at necropsy lipodystrophy patients are found to have Kupffer cells laden with lipid, this is a possible explanation of the findings. Alternatively, the receptor sites on the Kupffer cells are blocked by some other means.

${ }^{1}$ Mannik, M, and Arend, W P, fournal of Experimental Medicine, 1971, 134, $19 \mathrm{~s}$

2 Germuth, F G, and Rodriguez, E, Immunopathology of the Renal Glomerulus. Boston, Little Brown, 1973.

${ }^{3}$ Salky, N S, Mills, D, and DiLuzio, N R, fournal of Laboratory and Clinical Medicine, $1965,66,952$.

${ }^{4}$ Drivas, G, Uldall, P R, and Wardle, E N, British Medical fournal, 1975, 4, 743 .

${ }^{5}$ Wardle, E N, British fournal of Experimental Pathology, 1974, 55, 149.

Department of Medicine, Royal Victoria Infirmary, Newcastle upon Tyne, NE1 4LP

G DRIVAS, MD, research fellow

D N S KERR, MSC, FRCP, professor of medicine

C N WARDLE, MD, MRCP, regional physician

\section{Attempted suicide in labour}

While suicide in pregnancy is uncommon, attempted suicide seems as prevalent in pregnant as in non-pregnant women. ${ }^{1}$ But two reviews of attempted suicide in pregnancy ${ }^{12}$ found that attempts were uncommon in the third trimester and none had occurred in labour.

\section{Case report}

The patient, a 20-year-old unmarried English girl, had a past history of petit mal epilepsy, intermittent depression, and premenstrual tension. 